\title{
Cluster-randomised trial of a nurse-led advance care planning session in patients with COPD and their loved ones
}

\author{
Carmen H M Houben, ${ }^{1}$ Martijn A Spruit, ${ }^{1,2}$ Hans Luyten, ${ }^{3}$ Herman-Jan Pennings, ${ }^{4}$ \\ Vivian E M van den Boogaart, ${ }^{5}$ Jacques P H M Creemers, ${ }^{6}$ Geertjan Wesseling, \\ Emiel F M Wouters, ${ }^{1,7}$ Daisy J A Janssen ${ }^{1,8}$
}

- Additional material is published online only. To view please visit the journal online (http://dx.doi.org/10.1136/ thoraxjn-2018-211943).

For numbered affiliations see end of article.

\section{Correspondence to} Carmen H M Houben, Department of Research and Education, CIRO, 6085 NM Horn, The Netherlands; carmenhouben@ciro-horn.nl

Received 16 April 2018 Revised 24 October 2018 Accepted 12 November 2018 Published Online First 19 January 2019

\begin{abstract}
Rationale Advance care planning (ACP) is uncommon in patients with chronic obstructive pulmonary disease (COPD).
\end{abstract}

Objectives To assess whether a nurse-led ACP-

intervention can improve quality of patient-physician end-oflife care communication in patients with COPD. Furthermore, the influence of an ACP-intervention on symptoms of anxiety and depression in patients and loved ones was studied.

Finally, quality of death and dying was assessed in patients who died during 2-year follow-up.

Methods A multicentre cluster randomised-controlled trial in patients with advanced COPD was performed.

The intervention group received an 1.5 hours structured nurse-led ACP-session. Outcomes were: quality of patient-physician end-of-life care communication, prevalence of ACP-discussions 6 months after baseline, symptoms of anxiety and depression in patients and loved ones and quality of death and dying.

Results 165 patients were enrolled (89 intervention; 76 control). The improvement of quality of patient-physician end-of-life care communication was significantly higher in the intervention group compared with the control group ( $p<0.001)$. The ACP-intervention was significantly associated with the occurrence of an ACP-discussion with physicians within 6 months $(p=0.003)$. At follow-up, symptoms of anxiety were significantly lower in loved ones in the intervention group compared with the control group $(p=0.02)$. Symptoms of anxiety in patients and symptoms of depression in both patients and loved ones were comparable at follow-up ( $p>0.05$ ). The quality of death and dying was comparable between both groups $(p=0.17)$.

Conclusion One nurse-led ACP-intervention session improves patient-physician end-of-life care communication without causing psychosocial distress in both patients and loved ones.

\section{INTRODUCTION}

Check for updates

(c) Author(s) (or their employer(s)) 2019. № commercial re-use. See rights and permissions. Published by BMJ.

To cite: Houben $\mathrm{CHM}$, Spruit MA, Luyten $\mathrm{H}$, et al.

Thorax 2019;74:328-336.
Advance care planning (ACP) enables individuals to define goals and preferences for future medical care, to discuss these with family and healthcare providers and to record and review these preferences regularly. ${ }^{1}$ Despite the unpredictable disease trajectory and high mortality rate in patients with chronic obstructive pulmonary disease (COPD), ACP is uncommon. ${ }^{23}$ Important physician-reported barriers for ACP in COPD are lack of time, ${ }^{45}$ the unpredictable disease trajectory which makes it difficult for

\section{Key messages}

What is the key question?

- To study whether and to what extent one structured, nurse-led advance care planning (ACP) session can improve outcomes in patients with chronic obstructive pulmonary disease (COPD) and their loved ones.

What is the bottom line?

- One structured, nurse-led ACP session can facilitate patient-physician communication about end-of-life care without causing psychological distress in both patients and their loved ones.

Why read on?

- This study provides direction for further development and implementation of structured, nurse-led ACP in regular clinical care.

physicians to choose the appropriate timing for ACP and healthcare professionals' fear of causing psychosocial distress. ${ }^{6}$ ACP-interventions are likely to improve patient outcomes, for example increased discussions about end-of-life care and improved patient satisfaction. ${ }^{78}$ However, there is much less evidence about the long-term impact of $\mathrm{ACP}^{9}$ and, for example, the influence of ACP on quality of death and dying.

We designed this trial to assess whether a single, structured, 1.5 hours, nurse-led ACP-session can improve quality of end-of-life care communication between physicians and patients with COPD. Secondary objectives were to study the prevalence of ACP-discussions with physicians 6 months after ACP; changes in symptoms of anxiety and depression of patients and loved ones and quality of death and dying. We hypothesised that the ACP-intervention improves quality of end-of-life care communication and quality of death and dying in patients with advanced COPD without causing psychosocial distress in both patients and loved ones.

\section{METHODS}

\section{Design and setting}

This cluster-randomised controlled trial recruited patients from one academic and three general hospitals in the Netherlands between June 2013 
and October 2015. Patients in the intervention group received a 1.5 hours nurse-led ACP-session and patients in the control group received usual care. The methodology of this study was described in detail previously. ${ }^{10}$ The study was registered at the Dutch Trial Register (NTR3940), before the first patient was enrolled.

\section{Participants}

The study population consisted of a convenience sample of patients with advanced COPD (Global initiative for chronic Obstructive Lung Disease stage III, IV or quadrant D with a modified Medical Research Council (mMRC) dyspnoea grade $\geq 2)^{11}$ discharged after a hospital admission for an acute COPD exacerbation. Patients were asked to identify one to four loved ones for participation in the study. Exclusion criteria were: unable to complete questionnaires because of cognitive impairment or unable to speak and/or understand Dutch. All participants provided written informed consent. A sample size calculation with a level of significance of $5 \%$ and a power of $90 \%$ showed that 135 patients per group were needed in order to detect a predefined clinically relevant difference of 1 point increase in quality of communication (QOC) end-of-life care domain (QOC-EOL) score (SD estimated as 2.53 points) ${ }^{12}$ between the intervention and control group. The sample size calculation was not adjusted for clustering.

\section{Randomisation}

Cluster random sampling was used to assign 29 chest physicians to either the intervention or control group using sealed opaque envelopes. Participating patients received the intervention or usual care, depending on the randomisation of their chest physician. Patients were unaware of the randomisation of their chest physician.

\section{Intervention}

Eight respiratory nurse specialists received a 2-day training, which consisted of theoretical background of the importance of ACP, practicing end-of-life care communication skills and the structured ACP-session during the study. Adherence to the standardised protocol for the ACP-session was assessed (see online supplementary file). After preparation with the chest physician, nurses provided an ACP-session in the patient's home environment in the presence of the patient and loved one(s) within 4 weeks after discharge. The 1.5 hour intervention included several elements (online supplementary table E1) and was adapted to the patient's needs, by titrating information to the patient's preferences and paying attention to questions and concerns of both patients and loved ones. After the ACP-session, nurses completed a feedback form with the patient, which summarised patient's preferences for end-of-life care and end-of-life care communication, and remaining questions (online supplementary figure E1) and was provided to the patient, chest physician and general practitioner (GP). Finally, patients received a brochure about palliative care in COPD as developed by the Netherlands Lung Foundation.

\section{Procedures}

Patients were informed about the study during their hospital admission for a COPD exacerbation. After review of eligibility and consent, all patients and their loved ones were visited at home by a researcher $(\mathrm{CH})$ to collect baseline data. Afterwards, patients in the intervention group received the intervention and patients in the control group received care as usual. Six months after baseline, all patients were visited at home again to collect the follow-up data. Twelve and 24 months after enrolment all patients were called to assess survival status. If the patient died a bereavement interview was conducted with the participating loved one(s).

\section{Outcome measures}

The primary outcome measure was quality of end-of-life care communication 6 months after baseline, which was assessed using the end-of-life subscale of the QOC questionnaire. ${ }^{12}$ Secondary outcome measures were the prevalence of ACP-discussions with physicians 6 months after ACP; changes in symptoms of anxiety and depression of patients and loved ones and quality of death and dying. ${ }^{10}$ To measure prevalence of ACP-discussions, patients were asked at baseline and after 6 months whether they had a discussion about end-of-life care preferences with a healthcare professional and if so, with which healthcare professional they discussed their preferences. Symptoms of anxiety and depression were measured at baseline and 6 months in patients and loved ones using the Hospital Anxiety and Depression Scale (HADS). ${ }^{13}$ Quality of death and dying was assessed using the Quality of Death and Dying (QODD) questionnaire. ${ }^{14}$ Details about the questionnaires are provided in the online supplementary file.

Furthermore, the following other data were collected during home visits at baseline and 6 months after enrolment in patients in the intervention and control group: demographics (including age, sex, marital status, educational level); religion; body mass index (BMI); smoking history; self-reported comorbidities (Charlson Comorbidity Index); ${ }^{15}$ number of hospital admissions during the 6-month follow-up period; postbronchodilator forced expiratory volume in the $1 \mathrm{~s}$; use of long-term oxygen therapy and/or home-based non-invasive positive pressure ventilation; previous ACP-discussions with healthcare professionals; disease-specific health status (COPD Assessment Test) $;{ }^{16}$ generic health status (36-Item Short Form Health Survey) ${ }^{17}$ care dependency (Care Dependency Scale) ${ }^{18}$ and preferences for cardiopulmonary resuscitation and mechanical ventilation. ${ }^{19}$

\section{Statistics}

Categorical variables are described as frequencies, and continuous variables were tested for normality and are presented as mean (SD) or median (IQR). Baseline characteristics were compared between the intervention and control group using unpaired t-tests or Mann-Whitney U-tests for continuous variables and Chi-squared tests for categorical variables. Multilevel linear regression analysis was used to compare the difference in the mean change of the QOC end-of-life care communication domain score between the intervention and control group (random intercepts models were fitted). The difference in the mean change is defined as the difference between 6-month follow-up and baseline. By means of multilevel analysis, the nesting of patients within chest physicians was taken into account and variation among physicians with regard to the outcome measures could readily be assessed. Age and prior ACP-discussions were included as possible confounder into the regression models for quality of end-of-life care communication and general communication while they differed between the intervention and control group. To assess differences between the four hospitals involved, three dummy variables were included as covariates as well. In addition, for each item of the QOC end-of-life care communication domain, the proportion of patients that discussed this item was compared at baseline and 6-month follow-up between the intervention and control group using log-binomial models. The frequency of self-reported 


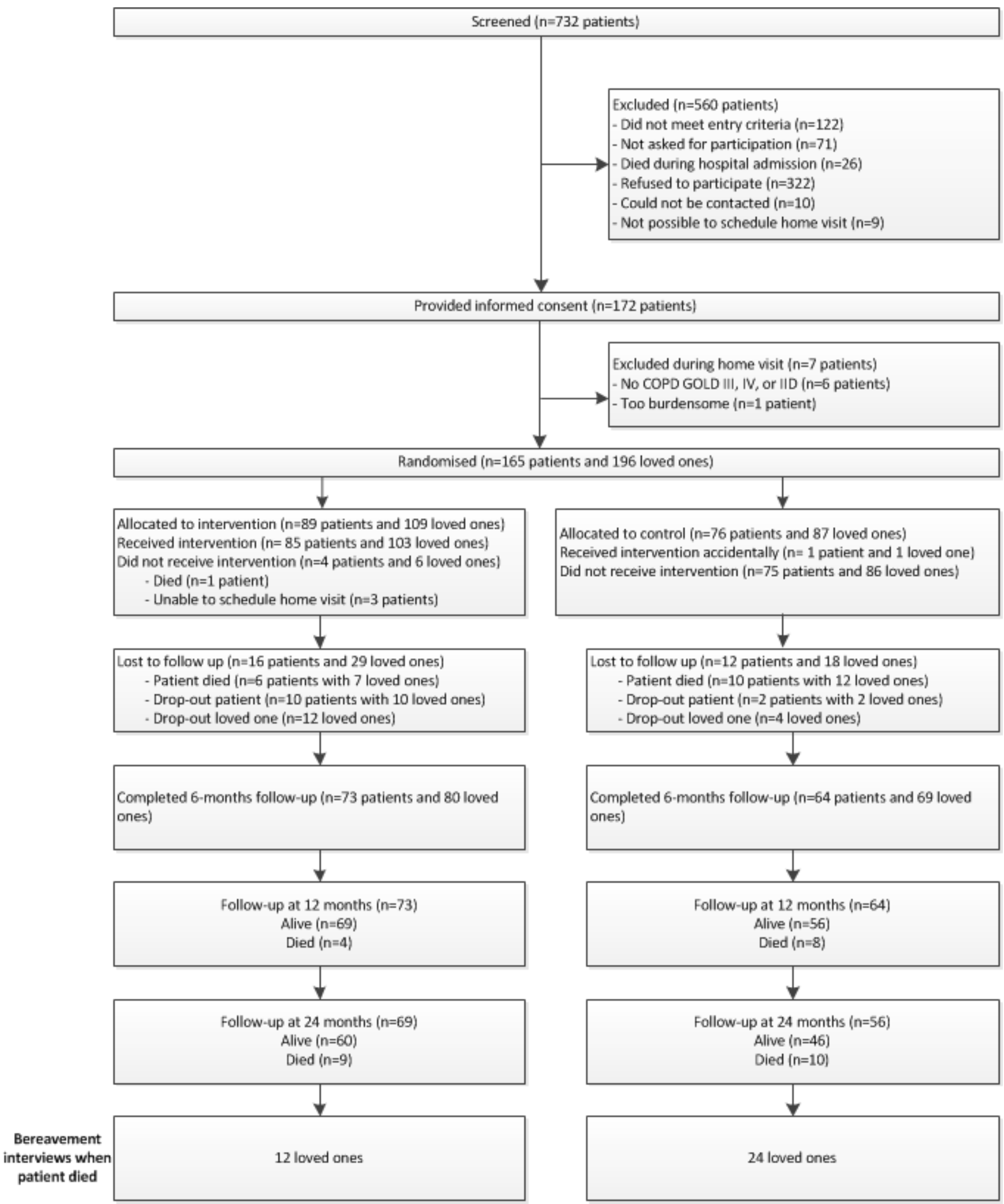

Figure 1 Flowchart. COPD, chronic obstructive pulmonary disease; GOLD, Global initiative for chronic Obstructive Lung Disease.

ACP-discussions between the intervention and control group at 6-month follow-up was compared using a log-binomial model.

To compare symptoms of anxiety and depression at 6-month follow-up between the intervention and control group, linear regression analyses were used in both patients and loved ones.
The nesting of patients within chest physicians was taken into account by means of multilevel analysis. Symptoms of anxiety or depression at baseline were included as covariate in both patients and loved ones. In addition, age was included as covariate in patients and gender as covariate in loved ones, because these 
Table 1 Baseline patient characteristics

\begin{tabular}{|c|c|c|}
\hline & $\begin{array}{l}\text { Intervention group } \\
(\mathrm{n}=89)\end{array}$ & Control group $(n=76)$ \\
\hline Number of physicians & $15(51.7 \%)$ & $14(48.3 \%)$ \\
\hline $\begin{array}{l}\text { Median (range) of patients per } \\
\text { physician }\end{array}$ & $5(1-12)$ & $3(1-17)$ \\
\hline Gender (male) & $44(49.4 \%)$ & $44(57.9 \%)$ \\
\hline Age (years), mean $(S D)^{*}$ & $65.7(9.2)$ & $69.5(9.0)$ \\
\hline BMI $\left(\mathrm{kg} / \mathrm{m}^{2}\right)$, mean $(\mathrm{SD})$ & $25.2(6.2)$ & $26.8(5.9)$ \\
\hline $\begin{array}{l}\text { Marital status (married/living with } \\
\text { partner) }\end{array}$ & $57(64.0 \%)$ & $52(68.4 \%)$ \\
\hline $\begin{array}{l}\text { Educational level (high school or } \\
\text { more) }\end{array}$ & $65(73.0 \%)$ & $58(76.3 \%)$ \\
\hline Current smokers & $15(16.9 \%)$ & $11(14.5 \%)$ \\
\hline $\mathrm{FEV}_{1}(\%$ predicted), mean (SD) & $43.5(16.9) \dagger$ & $43.1(14.5) \ddagger$ \\
\hline Charlson index (points), mean (SD) & $2.24(1.23)$ & $2.49(1.57)$ \\
\hline Long-term oxygen therapy & $36(40.4 \%)$ & $31(40.8 \%)$ \\
\hline $\begin{array}{l}\text { Home-based non-invasive positive } \\
\text { pressure ventilation }\end{array}$ & $10(11.2 \%)$ & $6(7.9 \%)$ \\
\hline Religious affiliation§ & $53(59.6 \%)$ & $50(65.8 \%)$ \\
\hline Previous ACP* & $13(14.6 \%)$ & $27(35.5 \%)$ \\
\hline $\begin{array}{l}\text { COPD Assessment Test (points), } \\
\text { mean (SD) }\end{array}$ & 23.1 (6.6)ף & $22.9(6.7)$ \\
\hline $\begin{array}{l}\text { Care Dependency Scale (points), } \\
\text { mean (SD) }\end{array}$ & $65.0(8.5) 9$ & $64.5(10.2)^{* *}$ \\
\hline HADS-A score (points), mean (SD) & $6.9(4.7)$ ๆ & $6.1(4.6)$ \\
\hline HADS-D score (points), mean (SD) & $6.7(4.2)$ ๆ & $6.7(4.1)$ \\
\hline $\begin{array}{l}\text { SF-36 physical component score } \\
\text { (points), mean (SD) }\end{array}$ & $19.7(9.6)$ & $20.3(9.8)$ \\
\hline $\begin{array}{l}\text { SF-36 mental component score } \\
\text { (points), mean (SD) }\end{array}$ & $40.8(15.1)$ & $40.8(15.0)$ \\
\hline Prefers CPR at baseline & $48(53.9 \%)$ & $35(46.1 \%)$ \\
\hline Prefers MV at baseline & $29(32.6 \%)$ & $18(23.7 \%)$ \\
\hline
\end{tabular}

\begin{tabular}{|c|c|c|}
\hline \multicolumn{3}{|l|}{ Loved ones } \\
\hline & $\begin{array}{l}\text { Intervention group } \\
(\mathrm{n}=109)\end{array}$ & Control group $(n=87)$ \\
\hline Gender (male) $+\dagger$ & $44(40.4 \%)$ & $22(25.3 \%)$ \\
\hline Age (years), mean (SD) & $53.7(15.2)$ & $56.5(14.4)$ \\
\hline \multicolumn{3}{|l|}{ Relationship to patient } \\
\hline Spouse & $54(49.5 \%)$ & $48(55.2 \%)$ \\
\hline Child & $37(33.9 \%)$ & $30(34.5 \%)$ \\
\hline Other‡¥ & $18(16.5 \%)$ & $9(10.3 \%)$ \\
\hline Education (high school or more) & $98(89.9 \%)$ & $74(85.1 \%)$ \\
\hline Current smokers & $29(26.6 \%)$ & $31(35.6 \%)$ \\
\hline Religious affiliation§ & $61(56.0 \%)$ & $47(54.0 \%)$ \\
\hline
\end{tabular}

Data presented as mean (SD) or number of patients (\%).

${ }^{*} \mathrm{P}<0.01$

$\neq \mathrm{N}=71$.

$\mathrm{\dagger N}=85$.

§Religious affiliation indicates having religious affiliation versus none.

१N $=88$.

${ }^{* *} \mathrm{~N}=75$;

$+\mathrm{P}<0.05$;

$\ddagger \neq 0$ ther=brother, sister, daughter-in-law, sister-in-law, brother-in-law, parent, cousin, foster-son, friend, ex-partner.

$\mathrm{ACP}$, advance care planning; $\mathrm{BMI}$, body mass index; CPR, cardiopulmonary resuscitation; FEV 1, forced expiratory volume in the $1 \mathrm{~s}$; HADS-A, Hospital Anxiety and Depression Scale, Anxiety subscale; HADS-D, Hospital Anxiety and Depression Scale, Depression subscale; MV, mechanical ventilation; SF-36, Short Form 36. differed between the intervention and control group. When the variance on physician-level was found to be not significant, the analysis was repeated as a linear regression analysis. Linear regression analyses for HADS-A and HADS-D were both adjusted for age and for baseline HADS-A or HADS-D score, respectively. To compare symptoms of anxiety and depression at baseline and 6-month follow-up within the intervention and control group, respectively, paired-samples t-tests were used.

Initially, multilevel linear regression analyses were performed to compare QODD-scores between the intervention and usual care group. However, due to the small number of deceased patients in both groups, which were nested within a large number of small clusters, the validity of the results obtained by this analysis could not be ascertained and therefore an independent samples t-test was used.

Statistics were compiled using SPSS, V.23.0 (SPSS, Chicago, Illinois, USA) and MLWin, V.3.00. A priori, a two-sided level of significance was set at $\mathrm{p}<0.05$. All analyses were done by intention to treat, using all available data from randomly assigned patients according to group assignment.

\section{RESULTS}

\section{Patient flow}

Total 610 of the 732 screened patients (83.3\%) were eligible, of which 539 patients were informed about the study and 165 patients participated (30.6\%). Gender was equally distributed between patients who provided informed consent and patients who refused participation $(\mathrm{p}=0.09)$. Total 89 patients were randomised to the ACP-intervention group and 76 to the control group. Total 138 patients (83.6\%) identified one loved one, 24 patients $(14.5 \%)$ identified two loved ones, 2 patients $(1.2 \%)$ identified three loved ones and 1 patient (0.6\%) identified four loved ones. Total 109 loved ones of patients randomised to the intervention group and 87 loved ones of patients randomised to the control group were included. Recruitment started in June 2013 and was discontinued in November 2015 due to budgetary issues. During the 6-month follow-up period the number of hospitalisations was $0.00(0.00$ 1.75) (median (IQR)) in the intervention group and $0.00(0.00$ 1.00) (median (IQR)) in the control group $(\mathrm{p}=0.90)$. After 24 months, 20 patients $(22.5 \%)$ in the intervention group had died and 28 patients $(36.8 \%)$ in the control group $(\mathrm{p}=0.10)$. Bereavement interviews were conducted with 12 loved ones in the intervention group and 24 loved ones in the control group (figure 1). Most important reasons for non-participation in the bereavement interviews were: drop-out of the loved one in an early stage of the study $(\mathrm{n}=8)$; logistical reasons $(\mathrm{n}=7)$ or the expected emotional burden of a bereavement interview $(n=5)$.

\section{Baseline characteristics}

At baseline, patients in the ACP-intervention group were younger than controls and had discussed ACP less frequently. Loved ones in the ACP-intervention group were more often male than loved ones in the control group. All other baseline characteristics were comparable between both groups (tables 1-3).

\section{Quality of communication}

QOC end-of-life care communication score significantly improved in the ACP-intervention group (2.37 points; 95\% CI 1.76 to 2.98; $\mathrm{p}<0.001)$, but did not change in the control group (0.32 points; $95 \% \mathrm{CI}-0.15$ to $0.80 ; \mathrm{p}=0.18$ ). Multilevel linear regression analysis showed that the mean difference in QOC end-of-life care communication score was significantly higher in the ACP-intervention group compared to the control group, when clustering for 
Table 2 Effect of intervention on quality of communication

\begin{tabular}{|c|c|c|c|c|c|c|c|}
\hline \multirow{2}{*}{$\begin{array}{l}\text { Mean difference } \\
\text { score }\end{array}$} & \multicolumn{2}{|c|}{ Intervention $(\mathrm{n}=71)$} & \multicolumn{2}{|c|}{ Control $(n=63)$} & \multirow[b]{2}{*}{ B } & \multirow[b]{2}{*}{$95 \% \mathrm{Cl}$} & \multirow[b]{2}{*}{$P$ values } \\
\hline & Mean (SD) & Median (IQR) & Mean (SD) & Median (IQR) & & & \\
\hline $\begin{array}{l}\text { QOC end-of-life care } \\
\text { domain }\end{array}$ & $2.34(2.56)$ & 1.29 (0.00 to 4.71$)$ & $0.32(1.88)$ & $0.00(-0.57$ to 1.00$)$ & 2.01 & 1.07 to 2.95 & $<0.001^{*}$ \\
\hline QOC general domain & $0.00(1.35)$ & $0.00(-0.50$ to 0.67$)$ & $0.17(1.48)$ & $0.17(-0.33$ to 0.83$)$ & -0.15 & -0.92 to 0.61 & $0.67^{*}$ \\
\hline
\end{tabular}

* Multilevel linear regression analysis clustered for physician (28 clusters) and adjusted for hospital, age and prior ACP.

$\mathrm{ACP}$, advance care planning; QOC, quality of communication.

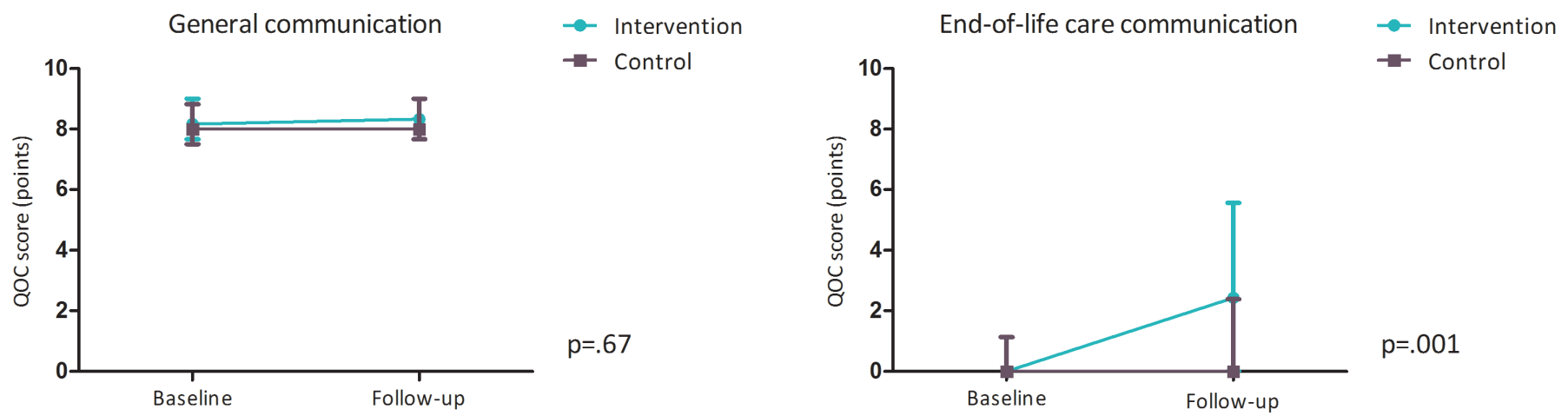

Figure 2 Quality of communication. Median (IQR) QOC questionnaire scores for the domains 'general communication' and 'communication about end-of-life care' at baseline and 6-month follow-up in the intervention and control group. P values based on multilevel linear regression analysis for mean difference score clustered for physician (28 clusters) and adjusted for hospital, age and prior ACP. ACP, advance care planning; Q0C, quality of communication.

physician (28 clusters) and adjusting for age and previous ACP-discussions (table 2; figure 2; online supplementary e-Table 2). The difference in QOC general domain scores was comparable between both groups (table 2; figure 2; online supplementary e-Table 2). The QOC item analyses showed that five QOC end-of-life care communication items were more frequently discussed at 6 months in the intervention group than in the control group. When items were discussed, the quality was fair well to well ${ }^{20}$ in both groups (figure 3). The quality of the item 'talking about your feelings about getting sicker' was significantly higher in the intervention group at 6 months compared to the control group $(p=0.04)$.
Six months after randomisation, 38 out of 73 patients in the ACP-intervention group (52.1\%) reported an ACP-discussion with another healthcare professional than the intervention nurse against 19 out of 64 patients in the control group (29.7\%) $(\mathrm{p}=0.003)$ (see online supplementary file for details).

\section{Symptoms of anxiety and depression}

Symptoms of anxiety improved significantly within the ACP-intervention group ( -1.1 points; $95 \% \mathrm{CI}-1.99$ to $-0.23 ; \mathrm{p}=0.01)$, but did not significantly change in the control group $(-0.4$

Table 3 Effect of intervention on symptoms of anxiety and depression in patients and loved ones is it possible to put intervention and number of patients on the same line?

\begin{tabular}{|c|c|c|c|c|c|c|c|c|c|c|}
\hline \multirow[b]{2}{*}{ Patients } & \multicolumn{5}{|l|}{ Baseline } & \multicolumn{5}{|l|}{ Follow-up } \\
\hline & $\begin{array}{l}\text { Intervention } \\
\mathrm{n}=72\end{array}$ & Control $n=64$ & B coefficient & $95 \% \mathrm{Cl}$ & $P$ value & $\begin{array}{l}\text { Intervention } \\
\mathrm{n}=72\end{array}$ & Control $n=64$ & B coefficient & $95 \% \mathrm{Cl}$ & $P$ value \\
\hline HADS-A & $6.6(4.7)$ & $6.0(4.5)$ & 0.25 & -1.28 to 1.78 & $0.75^{*}$ & $5.5(4.7)$ & $5.7(4.0)$ & -0.61 & -1.78 to 0.57 & $0.33 t$ \\
\hline HADS-D & $6.7(4.3)$ & $6.8(4.2)$ & -0.30 & -1.74 to 1.14 & $0.68^{*}$ & $6.4(4.7)$ & $6.3(3.9)$ & 0.25 & -0.82 to 1.32 & $0.65 \ddagger$ \\
\hline \multirow[t]{2}{*}{ Loved ones } & Baseline & & & & & Follow-up & & & & \\
\hline & $\begin{array}{l}\text { Intervention } \\
\mathrm{n}=80\end{array}$ & Control $n=69$ & B coefficient & $95 \% \mathrm{Cl}$ & $P$ values & $\begin{array}{l}\text { Intervention } \\
\mathrm{n}=78\end{array}$ & Control $n=69$ & B coefficient & $95 \% \mathrm{Cl}$ & $P$ values \\
\hline HADS-A & $6.2(4.3)$ & $6.7(4.3)$ & -0.21 & -1.59 to 1.17 & $0.76 \S$ & $5.2(3.6)$ & $6.7(4.8)$ & -1.25 & -2.33 to -0.18 & 0.029 \\
\hline HADS-D & $3.9(3.6)$ & $4.6(4.2)$ & -0.65 & -1.93 to 0.63 & $0.31 \S$ & $3.6(3.6)$ & $4.8(4.7)$ & -0.51 & -1.41 to 0.39 & $0.27^{* *}$ \\
\hline
\end{tabular}

Descriptive statistics presented as mean (SD).

* Linear regression analysis adjusted for age.

tLinear regression analysis adjusted for baseline HADS-A score and age.

‡Linear regression analysis adjusted for baseline HADS-D score and age.

$\S$ Linear regression analysis adjusted for gender.

१linear regression analysis adjusted for baseline HADS-A score and gender.

** Linear regression analysis adjusted for baseline HADS-D score and age.

HADS-A, Hospital Anxiety and Depression Scale, anxiety subscale; HADS-D, Hospital Anxiety and Depression Scale, depression subscale. 
Talking about your feelings about getting sicker

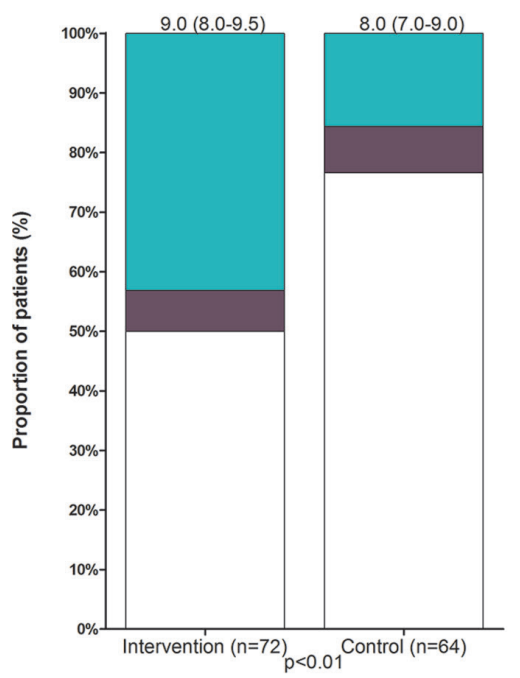

Talking about what dying might be like

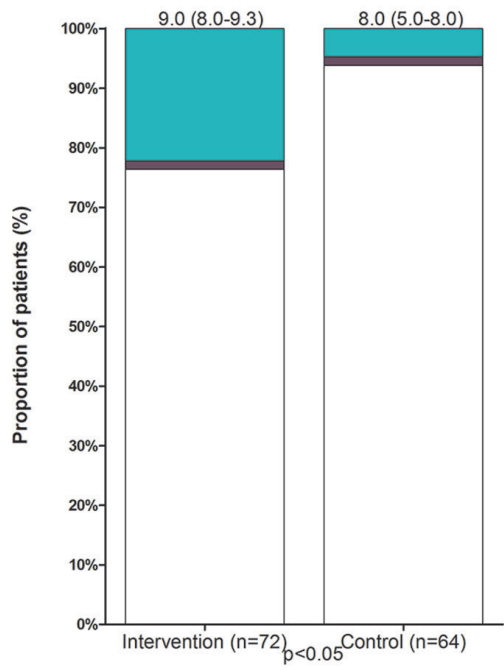

Asking about spiritual, religious beliefs

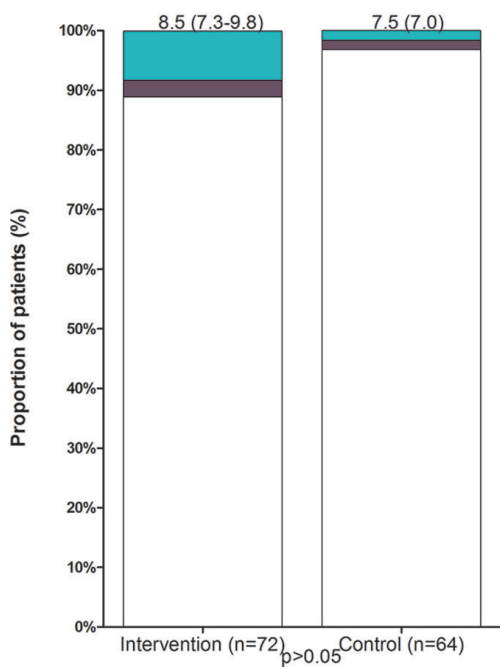

Talking about details if you got sicker

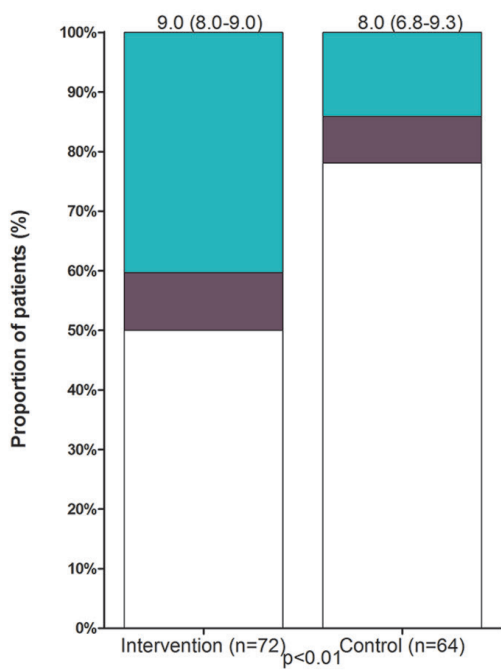

Involving you in treatment discussions about your care

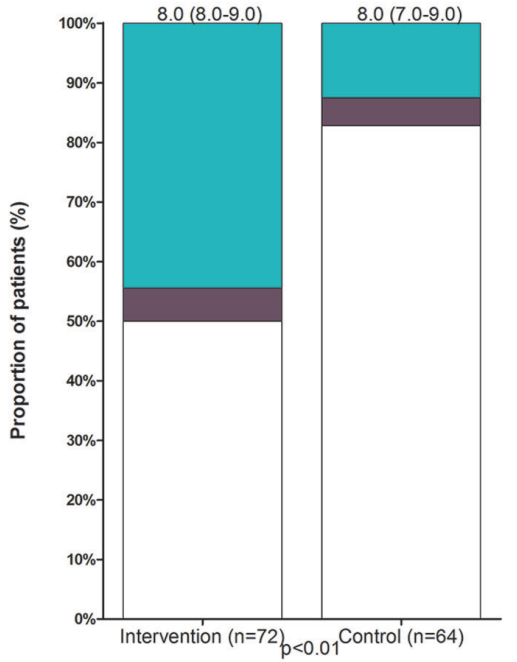

Talking about how long you have to live

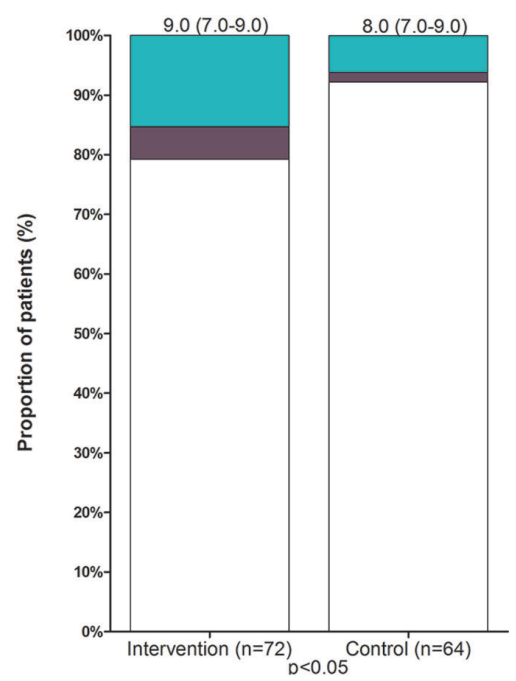

Asking you about important things in life

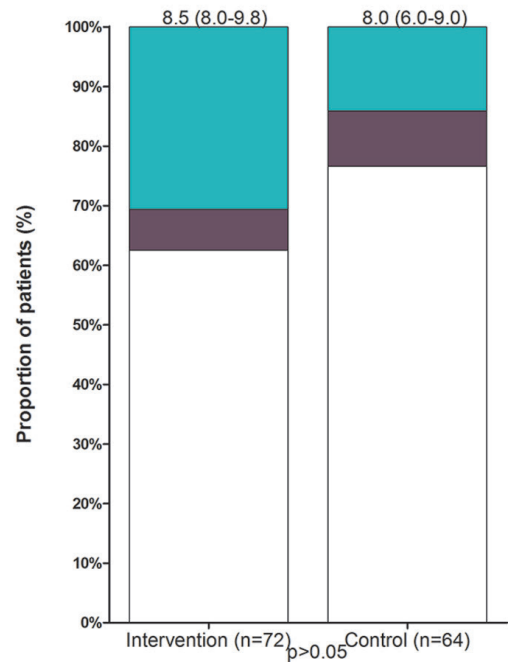

Figure 3 Quality of QOC end-of-life care items at 6-month follow-up. Frequency of discussing QOC end-of-life care items presented as proportion of patients (\%). For all discussed items the quality was analysed and reported as median (IQR). 75th percentile could not be calculated for the item 'asking about spiritual, religious beliefs' in the control group, because only two patients had discussed this item. Category 'quality poor-fairly well' is defined as QOC item scores $0-7$; category 'quality well' is defined as QOC items scores $8-10^{20}$. P values based on log-binomial models to compare the proportion of patients that had discussed the specific items at 6-month follow-up between intervention and control group. QOC, quality of communication. 
points; $95 \% \mathrm{CI}-1.38$ to $0.66 ; \mathrm{p}=0.48$ ). Symptoms of depression did not change $(p=0.60$ and $p=0.23$ for intervention and control group, respectively). Linear regression analysis showed no significant difference in symptoms of anxiety and depression between patients in both groups at 6-month follow-up, when adjusting for age and symptoms of anxiety or depression at baseline, respectively (tables 3).

Symptoms of anxiety improved significantly within the loved ones in the ACP-intervention group (intervention group: -0.9 points; $95 \% \mathrm{CI}-1.7$ to $-0.2 ; \mathrm{p}=0.02)$, but did not change in the control group ( -0.0 points; $95 \% \mathrm{CI}-0.9$ to $0.9 ; \mathrm{p}=0.98)$. Furthermore, symptoms of depression did not change within both groups $(p=0.60$ and $p=0.72$ for intervention and control group, respectively).

Linear regression analysis showed that loved ones in the intervention group had significantly less symptoms of anxiety in comparison with loved ones in the control group at 6-month follow-up, when adjusting for symptoms of anxiety at baseline and gender. Symptoms of depression at 6-month follow-up were comparable between loved ones in the intervention and control group, when adjusting for symptoms of depression at baseline and gender (table 3 ).

\section{Quality of death and dying}

The mean QODD-score in the intervention group was 80.01 (SD 8.57) and ranged from 61.25 to 91.11 . In the control group, the mean QODD-score was 74.71 (SD 11.51) with a range from 41.76 to 91.33 . Independent-samples t-test revealed no significant difference between both groups $(p=0.17)$. The results of the report-items are presented in online supplementary Table E3.

\section{DISCUSSION \\ Key findings}

One structured nurse-led ACP-session improved quality of end-oflife care communication between patients with COPD and their chest physicians. The intervention was positively associated with the occurrence of patient-reported ACP-discussions with healthcare professionals after 6 months. Moreover, symptoms of anxiety and depression did not increase following the intervention in both patients and loved ones. Actually, at 6-month follow-up, symptoms of anxiety were significantly lower in loved ones in the intervention group compared to the control group. Finally, the quality of death and dying was found to be comparable between both groups. However, the low number of participating loved ones of deceased patients in the intervention group was an important limitation for this analysis.

\section{ACP-intervention: strengths and opportunities for improvement}

The ACP-intervention was designed to improve ACP for patients with COPD by overcoming important barriers. First, the ACP-intervention was facilitated by nurses to overcome the physician-reported barrier of lack of time. Second, patients were recruited at an important milestone in the course of the disease and therefore at an appropriate moment to initiate $\mathrm{ACP} .^{21}$ Furthermore, ACP discussions are often avoided by healthcare professionals, because of fear to cause psychosocial distress. ${ }^{22}$ This study did not find evidence for this assumption and even suggests that ACP can reduce anxiety in loved ones. This is supported by ACP-studies in other populations, like patients with cancer and dementia. ${ }^{782324}$

The current intervention showed an increase in both prevalence and quality of patient-physician end-of-life care communication. However, based on the current study, no conclusions can be drawn about which components of the intervention were responsible for this effect. It could be that patients may feel more comfortable and confident in asking questions or starting a ACP-discussion with their chest-physician following the nurse-led intervention. So, the current intervention may support patient empowerment in engaging in ACP discussions. Additionally, in the ACP-study, chest physicians were provided a starting point to initiate an ACP-discussion during an outpatient visit, because patients already had a ACP-discussion with the nurse specialist and were aware of the fact that all feedback forms were sent to the chest physician. A previously published US trial, ${ }^{25}$ in which the intervention was limited to the use of a one-page feedback form showed, for example, an initial positive effect on the occurrence of ACP-discussions and quality of end-of-life care communication, but also showed that the intervention did not increase the documentation of subsequent ACP-discussions nor did it improve the documentation of advance directives in those patients who had died during the follow-up period. ${ }^{26}$ In fact, ACP is such a complex process that probably more components are needed to improve ACP. Future research is needed to reveal if the multicomponent intervention which is used in the ACP-study and combines a nurse-led ACP-session, a feedback form for chest physician and a palliative care brochure for patients can also improve ACP on the long term.

Despite these positive results, a considerable proportion of patients still did not report an ACP-discussion and patients reported that some topics had not been discussed. There are several explanations. First, the ACP-intervention focused mainly on behaviour change in healthcare professionals. However, ACP is a process between patients, loved ones and healthcare professionals. ${ }^{27}$ Therefore, optimal ACP interventions probably need to address all participants in this triangle. In fact, most patients will wait for caregivers to initiate discussion about the end-of-life, despite the fact that they have worries about their future or end-of-life care. ${ }^{28}$ Therefore, future ACP-interventions should also pay attention to patient empowerment, by, for example, providing information about the importance of ACP and how to initiate discussions with loved ones and healthcare professionals. Indeed, a recent study showed that a patient-centred ACP website (PREPARE) can increase ACP behaviour. Indeed, the use of PREPARE resulted in higher ACP-documentation and self-reported ACP engagement at follow-up. ${ }^{29}$ Finally, the ACP-intervention was a nurse-led intervention and therefore only nurses received an ACP-training. Although nurses prepared the ACP-session with physicians in advance and physicians did receive the feedback forms, they did not receive an ACP-training. The intervention would probably be more effective when also physicians had received training in order to develop effective ACP communication skills. Indeed, previous research found that workshops for physicians focusing on end-of-life communication skills are feasible in clinical practice and are effective for improving discussions about palliative care. ${ }^{30}$ Nevertheless, previous research has shown that when physicians discussed with their patients ACP-topics, the quality was rated high. ${ }^{31}$ This suggests that the problem is not so much the quality of end-of-life care communication, but the initiation of end-of-life care communication. Furthermore, the current literature recommends a multidisciplinary approach for ACP that includes multidisciplinary training to ensure high-quality palliative care for patients with COPD. ${ }^{32} 33$

The ACP-study did not improve the quality of death and dying as perceived by bereaved loved ones. Overall, the quality of death and dying was regarded as high in both groups, which may be indicative for a ceiling effect. ${ }^{34}$ In addition, it may reflect the high-quality of end-of-life care in the Netherlands. Indeed, a previous Dutch study showed that quality of death and dying is generally perceived 
to be good by bereaved loved ones and suggested that loved ones assessed this experience differently from healthcare professionals. ${ }^{35}$ Therefore, it would be interesting for future studies to also assess quality of death and dying from the healthcare professionals' point of view. Moreover, we did not assess whether the intervention stimulated ACP-discussions after 6 months. Therefore, in patients who died after 6 months follow-up we do not know whether and to what extent ACP conversations were held in the last phase of life. We acknowledge that ACP should be an ongoing process during the course of the disease.

\section{METHODOLOGICAL CONSIDERATIONS}

The present study has several strengths. First, patients were recruited from one academic and three general hospitals in the Netherlands to guarantee external validity. Second, we performed cluster analysis to prevent cross contamination between the intervention and control group and allocation was concealed to prevent systematic biases. It should be noted that the cluster randomisation was at the physician level, while the intervention was delivered by nurses, which may introduce the problem of cross contamination at the level of nurses. However, as we measured the primary outcome QOC about end-of-life care at the physician level, and considering the fact this outcome measure significantly improved in the intervention group and did not change in the control group, we assumed that the risk of cross contamination is negligible.

Several other limitations should also be considered. First, the recruitment of patients was challenging, as a consequence of gatekeeping and patient refusal. Those recruitment problems are a common concern in palliative care research and as a result study samples are smaller than planned in advance. ${ }^{36} 37$ After a recruitment period of 29 months, we decided to discontinue the recruitment period. Although the included sample size was too small based on the sample size calculation, we were able to find a significant effect of the intervention on the primary outcome measure quality of end-of-life care communication, as the effect size of the intervention was much greater than expected. Second, the participation rate was $31.4 \%$. Perhaps eligible patients who refused participation in this study were less willing to participate in ACP-discussions than patients who agreed participation, which may have influenced the current results. However, these patients may also refuse an ACP-discussion in clinical care, which may mitigate the importance of this limitation. Furthermore, the response rate conforms the previously reported difficulty of recruitment in palliative care studies. ${ }^{36}$ Third, in the sample size calculation, we did not account for clustering, which is a limitation in the study design. However, since the planned sample size was not reached, this is not particularly relevant for the current manuscript. Fourth, the single intervention in the current study has shown to be an adequate facilitator for the initiation of ACP between patients, families and physicians. However, we did not assess the long-term impact of our intervention on patient-physician end-of-life care communication. Fifth, the current study was based on a home-based intervention for which the nurses travelled to the patient's home to deliver the ACP-session. This could be a potential barrier in dissemination and implementation, because in clinical practice, it may not be feasible and too expensive to deliver the ACP-session in the home environment. We do not know whether results would have been comparable if the intervention had been offered in the hospital setting. In a study by Sinclair et al, an ACP-intervention was delivered in both the home and hospital setting. However, as the recruitment rate was lower than anticipated, the authors were not able to stratify the data in order to assess the impact of both settings on the study outcomes. ${ }^{38}$ In our opinion, the in-home character of our intervention could be a potential facilitator to promote ACP in less densely populated countries or in ethnic minorities. Indeed, previous research has shown that in-home interventions, in which healthcare professionals visit patients at home, are useful in those groups because access to routine healthcare is often limited. ${ }^{39-42}$

Sixth, the study did only assess communication about end-oflife care and the prevalence of ACP-discussions from the patient's perspective, which may raise the risk of recall bias. Previous research has, for example, shown major disagreement between patients and physicians about whether or not preferences for end-of-life care were discussed. ${ }^{2}$ Seventh, quality of death and dying was based on the loved one's perception of quality of death and dying and does not include objective measures of quality of end-of-life care. However, the QODD has found to be a validated instrument. ${ }^{14}$ Eighth, caution is warranted when interpreting the results of quality of death and dying, given the low mortality rates in both groups and the low willingness of loved ones to participate in bereavement interviews. Ninth, in the analysis we did not account for the fact that some of the patients had multiple participating loved ones. However, the majority of patients $(83.6 \%)$ had only one participating loved one. Tenth, the number of outpatient visits during the study is unknown. It might be that patients who visited the outpatient clinic were exposed to a greater change of receiving further follow-up ACP discussions. Finally, in the current study, GPs were not actively involved in the ACP-process. Their role was limited to the receipt of the feedback form from patients in the intervention group. Nevertheless, almost one-third of the patients in the intervention group who reported an ACP-discussion with a healthcare professional in the last 6 months had discussed these preferences with the GP.

\section{Conclusion and clinical implications}

One structured, nurse-led ACP session can facilitate patient-physician communication about end-of-life care without causing psychological distress in both patients and their loved ones. The results of this study provide direction for further development of ACP in patients with COPD. The project can be followed by implementation of structured, nurse-led ACP in regular clinical care and the intervention can possibly be implemented for other patients with advanced chronic life-limiting diseases, such as congestive heart failure or idiopathic pulmonary fibrosis. In addition, the training developed to train the respiratory nurse specialists in ACP could also be used to train other healthcare professionals, such as medical specialists, GPs, physician assistants and so on.

\section{Author affiliations}

'Department of Research and Education, CIRO, Horn, Limburg, The Netherlands ${ }^{2}$ Department of Respiratory Medicine, Maastricht University Medical Centre, NUTRIM School of Nutrition and Translational Research in Metabolism, Maastricht, The Netherlands

${ }^{3}$ Department of Research Methodology, Measurement and Data Analysis, University of Twente, Enschede, Overijssel, The Netherlands

${ }^{4}$ Department of Respiratory Medicine, St Laurentius Hospital, Roermond, Limburg, The Netherlands

${ }^{5}$ Department of Respiratory Medicine, VieCuri Medisch Centrum, Venlo, Limburg, The Netherlands

${ }^{6}$ Department of Respiratory Medicine, Catharina Hospital Eindhoven, Eindhoven, North Brabant, The Netherlands

${ }^{7}$ Department of Respiratory Medicine, Maastricht UMC+, Maastricht, The Netherlands

${ }^{8}$ Centre of Expertise for Palliative Care, Maastricht UMC+, Maastricht, The Netherlands 
Contributors $\mathrm{CHMH}, \mathrm{MAS}, \mathrm{EFMW}$ and DJAJ were involved in study concept and design. CHMH, H-JP, VEMB, JPHMC and GW were involved in acquisition of data. CHMH and HL did the statistical analysis. CHMH, MAS, HL and DJAJ interpreted the data. CHMH, MAS and DJAJ drafted the manuscript. All authors critically revised the manuscript for important intellectual content. All authors approved the final manuscript submitted and the authorship list. CHMH is the guarantor.

Funding This work was supported by the Netherlands Lung Foundation, Amersfoort, The Netherlands (Grant number 3.4.12.022).

Disclaimer No funding source had any role in design and conduct of the study; collection, management, analysis, and interpretation of the data and preparation, review or approval of the manuscript.

Competing interests MAS discloses speaker fees from GlaxoSmithKline, Boehringer Ingelheim, Novartis and AstraZeneca. EFMW discloses consulting and speaker fees from Nycomed, Boehringer Ingelheim, AstraZeneca, GlaxoSmithKline, Novartis and Chiesi. CHMH, HL, H-JP, VEMB, JPHMC, GW and DJAJ have nothing to disclose.

Patient consent Obtained.

Ethics approval Medical Ethical Committee of the Catharina Hospital Eindhoven (NL42437.060.12).

Provenance and peer review Not commissioned; externally peer reviewed.

\section{REFERENCES}

1 Rietjens JAC, Sudore RL, Connolly M, et al. Definition and recommendations for advance care planning: an international consensus supported by the European Association for Palliative Care. Lancet Oncol 2017;18:e543-e551.

2 Janssen DJA, Spruit MA, Schols J, et al. A call for high-quality advance care planning in outpatients with severe COPD or chronic heart failure. Chest 2011;139:1081-8.

3 Jabbarian LJ, Zwakman M, van der Heide A, et al. Advance care planning for patients with chronic respiratory diseases: a systematic review of preferences and practices. Thorax 2018;73:222-30.

4 Patel K, Janssen DJ, Curtis JR. Advance care planning in COPD. Respirology 2012;17:72-8.

5 Knauft E, Nielsen EL, Engelberg RA, et al. Barriers and facilitators to end-of-life care communication for patients with COPD. Chest 2005;127:2188-96

6 Voogt E, van der Heide A, Rietjens JA, et al. Attitudes of patients with incurable cancer toward medical treatment in the last phase of life. J Clin Oncol 2005;23:2012-9.

7 Brinkman-Stoppelenburg A, Rietjens JA, van der Heide A. The effects of advance care planning on end-of-life care: a systematic review. Palliat Med 2014;28:1000-25.

8 Houben CHM, Spruit MA, Groenen MTJ, et al. Efficacy of advance care planning: a systematic review and meta-analysis. J Am Med Dir Assoc 2014;15:477-89.

9 Johnson S, Kerridge I, Butow PN, et al. Advance Care Planning: is quality end of life care really that simple? Intern Med J 2017:47:390-4.

10 Houben $\mathrm{CH}$, Spruit MA, Wouters EF, et al. A randomised controlled trial on the efficacy of advance care planning on the quality of end-of-life care and communication in patients with COPD: the research protocol. BMJ Open 2014:4:e004465.

11 Global strategy for the diagnosis, management, and prevention of chronic obstructive pulmonary disease. Global Initiative for Chronic Obstructive Lung Disease. 2017:139.

12 Engelberg R, Downey L, Curtis JR. Psychometric characteristics of a quality of communication questionnaire assessing communication about end-of-life care. J Palliat Med 2006;9:1086-98.

13 Zigmond AS, Snaith RP. The hospital anxiety and depression scale. Acta Psychiatr Scand 1983;67:361-70.

14 Downey L, Curtis JR, Lafferty WE, et al. The quality of dying and death questionnaire (qodd): Empirical domains and theoretical perspectives. J Pain Symptom Manage 2010;39:9-22.

15 Charlson ME, Pompei P, Ales KL, et al. A new method of classifying prognostic comorbidity in longitudinal studies: development and validation. J Chronic Dis 1987:40:373-83.

16 Jones PW, Harding G, Berry P, et al. Development and first validation of the COPD Assessment Test. Eur Respir J 2009:34:648-54.

17 Ware JE, Sherbourne CD. The MOS 36-item short-form health survey (SF-36). I. Conceptual framework and item selection. Med Care 1992;30:473-83.
18 Dijkstra A, Tiesinga LJ, Goossen WT, et al. Further psychometric testing of the Dutch Care Dependency Scale on two different patient groups. Int I Nurs Pract 2002;8:305-14.

19 Janssen DJA, Spruit MA, Schols J, et al. Predicting changes in preferences for lifesustaining treatment among patients with advanced chronic organ failure. Chest 2012;141:1251-9.

20 Reinke LF, Slatore CG, Uman J, et al. Patient-clinician communication about end-of-life care topics: is anyone talking to patients with chronic obstructive pulmonary disease? J Palliat Med 2011;14:923-8.

21 Reinke LF, Engelberg RA, Shannon SE, et al. Transitions regarding palliative and end-of-life care in severe chronic obstructive pulmonary disease or advanced cancer: themes identified by patients, families, and clinicians. J Palliat Med 2008;11:601-9.

22 Brighton LJ, Bristowe K. Communication in palliative care: talking about the end of life, before the end of life. Postgrad Med J 2016;92:466-70.

23 Green MJ, Schubart JR, Whitehead MM, et al. Advance care planning does not adversely affect hope or anxiety among patients with advanced cancer. J Pain Symptom Manage 2015:49:1088-96.

24 Vandervoort A, Houttekier D, Vander Stichele R, et al. Quality of dying in nursing home residents dying with dementia: does advanced care planning matter? A nationwide postmortem study. PLoS One 2014;9:e91130.

$25 \mathrm{Au} \mathrm{DH}$, Udris EM, Engelberg RA, et al. A randomized trial to improve communication about end-of-life care among patients with COPD. Chest 2012;141:726-35.

26 Reinke LF, Feemster LC, MCDowell J, et al. The long term impact of an end-of-life communication intervention among veterans with COPD. Heart Lung 2017:46:30-4.

27 Janssen DJ, Engelberg RA, Wouters EF, et al. Advance care planning for patients with COPD: past, present and future. Patient Educ Couns 2012:86:19-24.

28 Heffner JE, Fahy B, Hilling L, et al. Attitudes regarding advance directives among patients in pulmonary rehabilitation. Am J Respir Crit Care Med 1996;154(6 Pt 1):1735-40.

29 Sudore RL, Boscardin J, Feuz MA, et al. Effect of the prepare website vs an easy-toread advance directive on advance care planning documentation and engagement among veterans: A randomized clinical trial. JAMA Intern Med 2017;177:1102-9.

30 Back AL, Arnold RM, Baile WF, et al. Efficacy of communication skills training for giving bad news and discussing transitions to palliative care. Arch Intern Med 2007:167:453-60.

31 Houben CH, Spruit MA, Schols JM, et al. Patient-clinician communication about end-of-life care in patients with advanced chronic organ failure during one year. J Pain Symptom Manage 2015;49:1109-15.

32 Duenk RG, Verhagen C, Dekhuiizen $\mathrm{P}$, et al. The view of pulmonologists on palliative care for patients with COPD: a survey study. Int I Chron Obstruct Pulmon Dis 2017:12:299-311.

33 Spathis A, Booth S. End of life care in chronic obstructive pulmonary disease: in search of a good death. Int I Chron Obstruct Pulmon Dis 2008;3:11-29.

34 Stiel S, Heckel M, Wendt KN, et al. Palliative care patients' quality of dying and circumstances of death-comparison of informal caregivers' and health-care professionals' estimates. Am J Hosp Palliat Care 2018:35:1023-9.

35 Gerritsen RT, Hofhuis JGM, Koopmans M, et al. Perception by family members and ICU staff of the quality of dying and death in the ICU: a prospective multicenter study in The Netherlands. Chest 2013;143:357-63.

36 Kars MC, van Thiel GJ, van der Graaf R, et al. A systematic review of reasons for gatekeeping in palliative care research. Palliat Med 2016;30:533-48.

37 Houben CH. Advance care planning in life-limiting illnesses [Doctoral dissertation: Maastricht University, 2018.

38 Sinclair C, Auret KA, Evans SF, et al. Advance care planning uptake among patients with severe lung disease: a randomised patient preference trial of a nurse-led, facilitated advance care planning intervention. BMJ Open 2017;7:e013415.

39 Beeber LS, Holditch-Davis D, Belyea MJ, et al. In-home intervention for depressive symptoms with low-income mothers of infants and toddlers in the United States. Health Care Women Int 2004:25:561-80.

40 Brennan AT, Thea DM, Semrau K, et al. In-home HIV testing and nevirapine dosing by traditional birth attendants in rural Zambia: a feasibility study. J Midwifery Womens Health 2014;59:198-204.

41 Pati S, Ladowski KL, Wong AT, et al. An enriched medical home intervention using community health workers improves adherence to immunization schedules. Vaccine 2015;33:6257-63.

42 Walkup JT, Barlow A, Mullany BC, et al. Randomized controlled trial of a paraprofessional-delivered in-home intervention for young reservation-based American Indian mothers. J Am Acad Child Adolesc Psychiatry 2009:48:591-601. 